\title{
Pancreatic pleural effusion associated with oncocytic carcinoma of the pancreas
}

\author{
D.W. England, ${ }^{1}$ F. Kurrein, ${ }^{2}$ E.L. Jones ${ }^{3}$ and C.W.O. Windsor ${ }^{1}$ \\ Departments of ${ }^{1}$ Surgery and ${ }^{2}$ Pathology, Ronkswood Hospital, Worcester and ${ }^{3}$ Department of Pathology, \\ Birmingham University Medical School, Birmingham, UK.
}

\begin{abstract}
Summary: A pancreatic pleural effusion is an uncommon presenting feature of pancreatic malignancy. A case is described where such an effusion was associated with an oncocytic carcinoma of the pancreas, a tumour which itself has been reported on only one previous occasion.
\end{abstract}

\section{Introduction}

Pancreatic pleural effusion is an increasingly recognized complication of benign pancreatic disease. ${ }^{1}$ We report a case of pancreatic pleural effusion where the cause was an extremely rare type of pancreatic carcinoma.

\section{Case report}

A 64 year old man presented with a 7-week history of continuous epigastric pain, vomiting and weight loss. A separate left loin pain resolved with the passing of a urinary calculus. Examination revealed a thin, ill looking patient with a large epigastric mass and a large, left sided pleural effusion. Laboratory investigations showed a haemoglobin of $13.1 \mathrm{~g} / \mathrm{dl}$, erythrocyte sedimentation rate of $47 \mathrm{~mm}$ in the first hour, bilirubin $11 \mu \mathrm{mol} / 1$, alkaline phosphatase $405 \mathrm{IU} / 1$, aspartate transaminase $36 \mathrm{IU} / 1$, albumin $23 \mathrm{~g} / \mathrm{l}$, calcium 2.62 (corrected 3.04 ) $\mathrm{mmol} / \mathrm{l}$ and serum amylase $<160 \mathrm{IU} / 1$. A uniformly blood stained pleural aspirate had an amylase concentration $>9600$ IU/l. Endoscopy showed the second part of the duodenum to be indented from without, with secondary ulceration. Ultrasound scanning demonstrated a solid mass below the pancreas. Laparotomy findings were of an irresectable $12 \times 10 \times 4 \mathrm{~cm}$ tumour arising from the body of the pancreas which was closely adherent to the duodenum but causing no significant obstruction and extending into the base of the small

Correspondence: D.W. England, F.R.C.S.

Accepted: 13 January 1988 bowel mesentery. There was a small amount of ascitic fluid and the liver was clear. Needle biopsies were taken for tissue diagnosis. Post-operatively the patient's condition deteriorated with rapid reaccumulation of the pleural effusion and gross ascites. He died three weeks later. Examination of both biopsy specimens and post-mortem material showed a firm, pale tan, lobulated tumour composed of groups and solid sheets of large, polygonal cells with abundant granular cytoplasm (Figure 1). Nuclei were large and irregular with prominent nucleoli. The cells were grouped into irregular patterns not related to lobulation. The cytoplasm was acidophilic although a few groups of cells had pale eosinophilic cytoplasm (Figure 2). Superficially the appearances were suggestive of granular cell myoblastoma. However, the tumour cells were negative with the periodic acid Schiff sequence (PAS) and did not stain for S100 protein. The appearances were those of an oncocytic carcinoma of the pancreas.

\section{Discussion}

The English language literature contains only one previous report of a pancreatic pleural effusion associated with a pancreatic carcinoma. ${ }^{2}$ Small, self-limiting pleural effusions due to a chemical irritation of the diaphragmatic lymphatics occur commonly with acute pancreatitis but large, chronic effusions characterized by elevated amylase and protein, recurrence after aspiration and due to a pancreatic fistula are rare. The most common

(C)The Fellowship of Postgraduate Medicine, 1988 


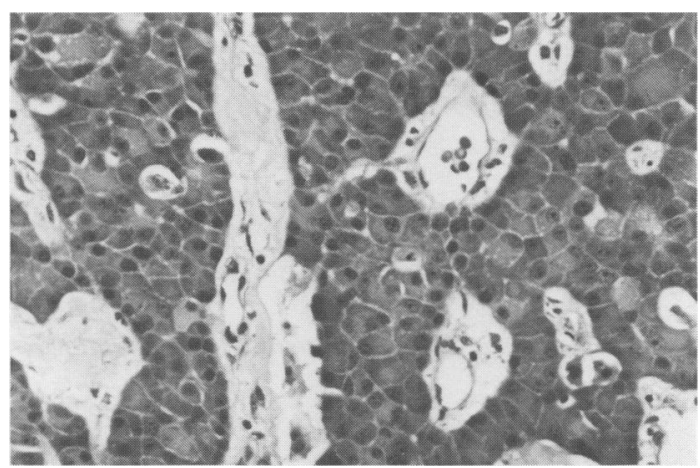

Figure 1 Solid sheets of large polygonal tumour cells arranged around thin-walled vascular channels. $\mathrm{H} \& \mathrm{E} \times 201$.

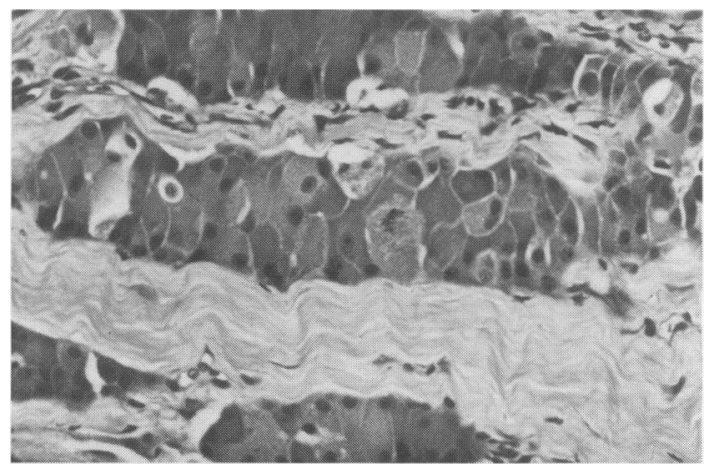

Figure 2 Tumour cells showing granular acidophilic cytoplasm. H\& E $\times 201$.

aetiology is chronic pancreatitis, more than $80 \%$ occurring in alcoholics. ${ }^{1}$ Other causes of amylase rich pleural effusions include acute pancreatitis, ${ }^{3}$ trauma, ${ }^{4}$ ovarian carcinoma, ${ }^{5}$ and ruptured oesophagus $^{6}$ (the latter three containing salivary amylase). For a long time the mechanism of pancreatic pleural effusion was uncertain but it is now clear that posterior duct disruption leads to internal fistula formation with fluid tracking retroperi-

\section{References}

1. Cameron, J.L., Kieffer, R.S., Anderson, W.J. et al. Internal pancreatic fistulas; pancreatic ascites and pleural effusions. Ann Surg 1976, 183: 587-593.

2. Sankarankutty, M., Baird, J.L., Dowse, J.A. \& Morris, J.S. Adenocarcinoma of the pancreas with massive pleural effusion. Br J Clin Pract 1978, 32: 294-297.

3. Razzaque, M.A., Hussain, S.A., Nossain, Z. \& Kumar, G.K. Pleural effusion with pancreaticopleural fistula. Am J Gastroenterol 1977, 68: 84-87.

4. Saugier, B., Emonot, A., Plauchu, M. \& Galy, P. Effusions rich in amylase without pancreatitis. Nouv Presse Med 1976, 5: 2777-2780.

5. Corlette, M.B., Dratch, M. \& Sorger, K. Amylase elevation attributable to an ovarian neoplasm. Gastroenterology 1978, 74: 907-909. toneally alongside the aorta or oesophagus into the chest. $^{7}$ Anterior disruptions lead to pancreatic ascites, here demonstrated by the rapid ascitic accumulation post biopsy. However, the majority of duct disruptions occur in acute pancreatitis where the fluid is surrounded and enclosed by inflamed organs with resultant pseudocyst formation.

The chief factor in diagnosis is the recognition that pleural effusions of obscure aetiology may have a pancreatic origin ${ }^{8}$ confirmed by testing of pleural fluid for amylase. The serum amylase is not necessarily elevated. Investigations should include endoscopic retrograde cholangiopancreatography to demonstrate the fistula and bearing in mind the possibility of carcinoma, abdominal ultrasound or computed tomographic scanning.

Of non-malignant cases up to $50 \%$ can be treated conservatively by repeated pleural aspiration and general supportive therapy, particularly aimed at maintenance of nutritional status. ${ }^{7}$ Failure to respond to these measures and malignancy are indications for surgery. This requires the identification of the fistula (usually by intra-operative pancreatography) and its ligation or excision plus treatment of the primary pathology, either partial pancreatectomy or drainage depending on the situation.

Oncocytoma has been described in a number of organs since Jaffe in 1932 first used the term for a tumour of salivary gland. ${ }^{9}$ The oncocyte is a large cell with abundant, finely granular cytoplasm, the granularity being due to large numbers of mitochondria. These tumours are usually benign but clearly malignant examples do occur. ${ }^{10}$ In 1983 a case of this type was first reported in the pancreas. ${ }^{11}$ Oncocytes are seen in the epithelium of the pancreatic duct system and are probably the cells of origin of the tumour.

Thus, this is the second recorded case of oncocytic carcinoma of the pancreas, here associated with the equally unusual malignant pancreatic pleural effusion.

6. Lehrner, L.M., Ward, J.C., Karn, R.C. et al. An evaluation of the usefulness of amylase isoenzyme differentiation in patients with hyperamylasaemia. $\mathrm{Am}$ J Clin Pathol 1976, 66: 576-587.

7. Cameron, J.L. Chronic pancreatic ascites and pancreatic pleural effusions. Gastroenterology 1978, 74: 134-140.

8. Light, R.W. \& Ball, W.C. Glucose and amylase in pleural effusions. JAMA 1973, 225: 257-260.

9. Jaffe, R.H. Adenolymphoma (onkocytoma) of parotid gland. Am J Cancer 1932, 16: 1415-1423.

10. Hamperl, H. Benign and malignant oncocytoma. Cancer 1962, 15: 1019-1027.

11. Huntrakoon, M. Oncocytic carcinoma of the pancreas. Cancer 1983, 51: 332-336. 